The Middle Muddle: Conceptualizing and Measuring the Global Middle Class

Arjun Jayadev, Rahul Lahoti and Sanjay G. Reddy

WORKING PAPER 2015-06

DEPARTMENT OF ECONOMICS

UNIVERSITY OF MASSACHUSETTS BOSTON 


\title{
The Middle Muddle: Conceptualizing and Measuring the Global Middle Class
}

\author{
Arjun Jayadev, Rahul Lahoti and Sanjay Reddy
}

October 18, 2015

\begin{abstract}
Interest in the emergence of a global middle class has resulted in a number of attempts to identify and enumerate who belongs to it . Current research provides wildly different estimates about the size and evolution of the global middle class because of a lack of consensus on appropriate identification criteria for a person to be deemed to be middle class. We identify three competing and often conflated understandings in the literature on the subject. We further argue that for at least two of these understandings, the literature has been using inappropriate thresholds for identification. Using data from the Global Consumption and Income Project, we provide estimates of the size, composition and evolution of the global middle class for three competing understandings and contrast these to existing estimates.
\end{abstract}




\section{Introduction}

Simply put, the American middle class is under great strain today, and the outlook for major improvements in the near future is somewhat grim unless we take action. This is a matter of great concern for our country. The middle class is the backbone of America's economy and its democracy. So the state of the middle class is in many ways a proxy for the state of the union.

Joseph E Stiglitz, Testimony to Congress, February 24, 2015

For Joseph Eugene Stiglitz, whose extraordinary contributions to intellectual enquiry and the pursuit of social justice we honor in this article, the condition and prospects of the middle class have always been topics of great interest. From his earliest work on credit and labor markets to his most recent work on the often savage costs of inequality, the economic and social condition of the middle class has always been an urgent intellectual and political concern, underpinned by his personal origins in Gary, Indiand ${ }^{1}$ In this, as with other topics, Joe's insights have contributed immensely to clarifying problems and solutions and to opening lines of enquiry.

The pivotal role of the middle class has, of course, been a long-standing theme in social theory and political analysis, from Aristotle's description of the ideal state as comprising a large middle grouping that moderates political extremes ${ }^{2}$ to modern considerations of the median voter theorem in political and economic decision making. Furthermore, there may be economically instrumental reasons to be concerned about the middle class as the grouping that generates new entrepreneurs, emphasizes economically "useful" values such as education and thrift and is the main source of consumption and aggregate demand for goods and services.

Changing patterns of income and consumption distribution within and across countries have brought these concerns to contemporary popular consciousness. Thus, for example, anxieties about the disappearance of a middle class, increasing job and income polarization and the attendant impacts on social and political stability and on aspirations for individual and collective progress have been an important theme in academic and popular discourse, especially in the U.S. where the ?American Dream? has been seen as being at stak $\oint^{3}$. At the same time, increased global trade and

\footnotetext{
${ }^{1}$ On the relevance of these origins to his subsequent intellectual trajectory see his Nobel Prize biography, at http://www.nobelprize.org/nobel_prizes/economic-sciences/laureates/2001/stiglitz-bio.html

${ }^{2}$ As he put it in his Politics "... city ought to be composed, as far as possible, of equals and similars; and these are generally the middle classes. Wherefore the city which is composed of middle-class citizens is necessarily best constituted in respect of the elements of which we say the fabric of the state naturally consists. And this is the class of citizens which is most secure in a state, for they do not, like the poor, covet their neighbors' goods; nor do others covet theirs, as the poor covet the goods of the rich; and as they neither plot against others, nor are themselves plotted against, they pass through life safely. Wisely then did Phocylides pray- 'Many things are best in the mean; I desire to be of a middle condition in my city?. Thus, it is manifest that the best political community is formed by citizens of the middle class, and that those states are likely to be well-administered in which the middle class is large, and stronger if possible than both the other classes, or at any rate than either singly; for the addition of the middle class turns the scale, and prevents either of the extremes from being dominant? (See Benjamin Jowett's translation, Book Four, Part XI, http://classics.mit.edu/Aristotle/politics.4.four.html.

${ }^{3}$ Some representative academic explorations of the disappearing middle class, very far from exhaustive, include (Frank, 2007, Esteban and Ray, 1994, Duclos et al. 2004, Pressman 2007, Stiglitz, 2012 Autor et al. 2008 Wolfson 1994). For a characteristic meditation on the impact of the thinning of the middle class on politics and society Ed Luce, 'It's Still the Middle Class, Dumbo', Financial Times, October 4th, 2015
} 
international financial integration, accompanied by reductions in the cost of communication and transportation have resulted in increases in economic interdependence. As one consequence there has been substantial interest in the emergence of a "global middle class". This grouping, it has been suggested, is a new social formation of world-historical importance, its emergence portending huge implications, for consumption, growth, political dynamics within and between countries, cultural flows and norms, and the ecological health of the planet. The undoubtedly critical changes in the structure of the world economy, in particular in terms of the growing role of the developing countries and of newly affluent populations within them (with the developing countries beginning to account for the majority of global growth beginning in the first decade of the current century), have given great relevance to this question.

Nevertheless, we have a tenuous and contested understanding of the size, composition and evolution of the middle class within given societies and the world as a whole. This is despite great improvement in the availability and quality of relevant data from across the world in the last two decades.

The primary reason for this is that the middle class is a complex and contested concept and one that defies easy conceptual clarity and measurement although this is not always acknowledged. Surveys in the US show a large fraction of people in the upper 10th and the bottom 10th of the distribution often self-identify as 'middle-class' (Cashell, 2008; Taylor et al., 2008). . Although this may be an especially pronounced phenomenon in the US, in light of the role within it of the republican ideal of social equality (commented on by early observers such as Alexis de Tocqueville) it is indicative of the difficulties involved in empirical analysis of social concepts that have both "objective" and subjective elements 4 Similarly, very small fractions of the population identify as lower or upper class. Even if one were to eschew subjective identification in favor of objective, measurable categories, it is unclear what characteristics to take into account. An individual's race, education, income, wealth, consumption patterns, family background, manners and habits, and ability to engage in social and political life can all be components of perceived or actual belonging to the middle class and it is certainly not clear how to integrate these different considerations into a single concept.

If identifying a middle class is difficult within a country, problems of identification multiply when trying to capture the middle class in a global context. Even if one were to find broad agreement on the characteristics of middle class living in the US, say, it would not be clear that these ought to be made the same when applied to other high income countries and it would be even less so for other countries. The appropriate criteria to use when going beyond individual countries to determine membership in a cross-national global middle class, spanning diverse social, cultural and political contexts, is all the more obscure. In particular, criteria relating to command over resources may be compatible with separate country-by-country assessment, but criteria relating to the ability to participate in a common social, cultural and political sphere of global interactions, require the identification of the requirements of such participation globally $\left.\right|^{5}$.

\footnotetext{
${ }^{4}$ Here, of course the distinction between a class-for-itself and a class-in-itself from Lukács and Lukács (1971) is relevant

${ }^{5}$ This is not a simple matter of absolute and relative classification. A given absolutely defined capability (e.g. to be able to participate meaningfully in the sphere of cultural production of consequence to one?s society) may depend on commodity requirements that are relative in the space of commodities and dependent upon specified contextual boundaries. For instance, whereas previously it may have required knowledge of and ability to relate and modify an oral tradition in one?s own language, in today's global context it might require access to a computer and knowledge of the English language or another prevalent tongue.
} 
Perhaps in light of the difficulties associated with conceptualizing and operationalizing broader sociological interpretations of class efforts by economists aimed at measuring the size of the middle class have usually relied on purely income-based definitions ${ }^{6}$. These measures include ranges based on absolute income or consumption, incomes relative to the median or to the mean, incomes relative to the poverty line or to a specified percentile or proportion of the income distribution (for example, the middle $40 \%$ ).

While using an income-based measure within a country may be reasonable for certain purposes and given certain constraints (in particular the severe limitations of internationally comparable data on the intra-national distribution of non-income attainments) doing so in a global context is fraught with conceptual difficulties. A review of the academic and policy literature and the popular press suggests at least three competing definitions of an emerging global middle class that are often inappropriately conflated in the economic literature. Indeed, these may be at the source of the somewhat elusive and seemingly chimerical quality of the global middle class.

First, when speaking about the the emerging global middle class a researcher may be using a purely relative concept, referring to "middle" of the global income or consumption distribution (see for example (Easterly, 2001; Quah, 1996)). This perspective has the most apparent straightforwardness but is not very easy to justify in the global context. It corresponds to absolutely very low thresholds, which might not suffice for even basic attainments, let alone the conditions for meaningful participation in world society.

Second, and more commonly, the emerging global middle class is defined according to absolute income thresholds, as a grouping that enjoys a certain standard of living (e.g. those who now enjoy income levels in their home countries which enable them to be free from severe economic deprivation and to spend their income in ways that reflect broader aspirations as a result of growth) without rising above the threshold of affluence. This idea might be given a justification involving, for instance, freedom from certain forms of material lack combined with discretionary resources for various purposes or the requirements for being perceived as a certain sort of "respectable" consumer or citizen. Absolute money thresholds can still therefore ultimately be linked to contextual considerations. Although economic, social and cultural considerations are complexly linked in relation to this concern, for simplicity we refer to absolute thresholds based on these motivations as corresponding to a "sociological" conception of the middle class.

Third, and perhaps most obscurely, the emerging global middle class is sometimes viewed as a category of persons responsible for constituting a consumer market possessing certain quantitative or qualitative features (e.g. in terms of its contribution to global aggregate demand or the demand of specific industries). We can think of this as involving the idea of middle class as mover (whether or not prime mover). Although these ideas can overlap descriptively and be connected causally, they are distinct.

In what follows we refer to these as Global Middle Class Concept 1, Global Middle Class Concept 2 and Global Middle Class Concept 3 (with apologies to Branko Milanovic) (Milanovic, 2006). These are certainly not the only ways of identifying members of the middle class using economic data but they are prominent in the literature and so we focus on them in order to provide clarification. A

${ }^{6}$ (Bardhan, 1999 1984) uses broader Marxian categories to analyze Indian class formations. The work of social theorists and others, although enormously influential in sociology, appears not to have much impact in economics (Bourdieu 2011; Aron, 1950, Parsons, 1940 Runciman, 1974). Some thoughtful recent exceptions include (Atkinson and Brandolini, 2011, Blank 2010) 
focus on any one of these concepts must be suitably justified and moreover what follows, or doesn't, from a specific choice must be understood in order to use them as a basis for generating thresholds for operationalization and measurement.

The conceptual underpinnings are important because they form the basis for deciding the thresholds for operationalization and measurement. Perhaps in part because the underlying motivations of the exercise have been both conflated and left unclarified, researchers have employed wildly differing income or consumption thresholds in defining the global middle class. It is interesting in this regard to note that the first two empirical examinations of the global middle class employ income intervals (defined by lower and upper thresholds) that have no overlap! Thus (Banerjee and Duflo, 2008) defines these thresholds as occurring between $\$ 2$ PPP and $\$ 10$ PPP (in 2005 PPP terms) per day on the grounds that this corresponds to those who are not defined as poor by the World Bank's poverty line thresholds while not being wealthy) 7 , while (Milanovic and Yitzhaki, 2002) define the threshold as between $\$ 12 \mathrm{PPP}$ and $\$ 50 \mathrm{PPP}$ (in 1993 PPP terms) per day on the basis of the average incomes of Brazil and Portugal respectively.In the recent past, there have been more entrants and contestants in the definition of this group: (Kharas, 2010, Kharas and Gertz, 2010, Lopez-Calva and Ortiz-Juarez, 2014) use $\$ 10$ as the lower cutoff for the middle class; with the latter defending this on the basis that at that level, the non-poor in Latin America have only a one in ten chance of returning to poverty (Ferreira et al. 2012). At the upper end, the two differ- with Kharas and Gertz setting it at $\$ 100$ PPP per day (The upper bound is chosen as twice the median income of Luxemburg, the richest advanced country) while Lopez-Calva and Ortiz-Juarez set it at $\$ 50$ PPP (which excludes only the top 5\% of Latin American households) . Ravallion (2010) defines the middle class group as possessing incomes between $\$ 2$ PPP and $\$ 13$ PPP across the developing world. Nancy Birdsall (Birdsall, 2010) uses a hybrid definition, again choosing $\$ 10$ PPP as absolute lower threshold and using a relative cut-off at the upper end by excluding the richest 5 percent of individuals within any country. Researchers from the ILO specify cutoffs of $\$ 4$ PPP to $\$ 13$ PPP per day (Kapsos et al., 2013). Finally, there are other approaches which eschew dollar values altogether and use indicators such as car consumption (Dadush and Ali, 2012) to identify the global middle class.

Unsurprisingly, these different approaches and intuitions give rise to wildly differing estimates and understandings of the global middle class. Figure 1 shows that the global middle class in 2013 could be as large as $42 \%$ of the global population or as small as $19 \%$ depending on which of the extant definitions we use. . One might be forgiven for seeing these results as reflecting something of a free for all. There is almost no overlap between the Banerjee-Duflo, Ravallion and ILO definitions on the one hand and the Milanovic-Yitzhaki, Kharas, Birdsall and Lopez-Calva/Ortiz-Juarez definitions on the other. Thus using the (Kharas, 2010) definition suggests that the global middle class includes 1.5 billion people while the (Banerjee and Duflo, 2008) definition would peg it as 2.9 billion. In addition, middle class definitions based on relative incomes add another layer of confusion. As (Birdsall, 2012) notes: "Depending on your point of view, the middle class in Brazil includes everyone in the three middle quintiles (Easterly, 2001) about 114 million people in 2009 or everyone with per capita daily income between $\$ 10$ and $\$ 50$ (World Bank, 2012) about 61 million people, with an overlap in the case of Brazil in 2009 of only 36 million people." It is of no surprise then that popular articles describe the global middle class as 'elusive' and researchers often dismiss attempts to define it are 'arbitrary'. Needless to say, not only the level but also the regional and national composition and trend over time of the number of persons in the middle class can be greatly affected by the choice

\footnotetext{
${ }^{7}$ This definition is also used by Sumner 2012 ) in his analysis of the global middle class
} 
of identification criteria, so this is no mere distinction without a difference 8 . If it matters to assess the membership of the global middle class at all, then these sizable variations ought to give reason for concern.

Figure 1: Different Estimates of the Size of the World Middle Class

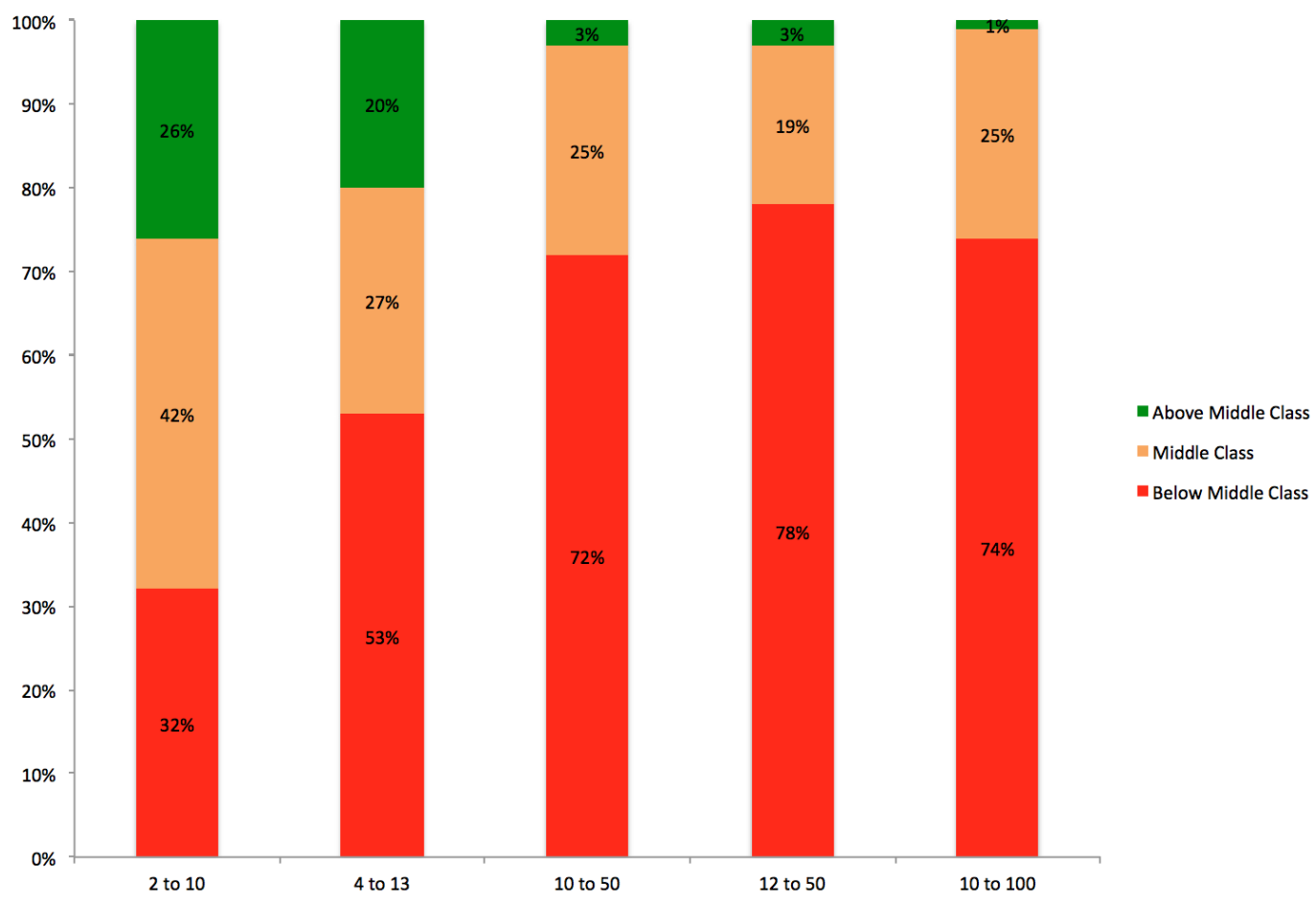

2-10 (2005 PPP): Banerjee and Duflo (2008)cut offs based on 'Developing world Middle class' 10-50 (2005 PPP): Lopez-Calva and Ortiz-Juarez (2014) cut offs based on 'Latin American Middle Class' 12-50 (1993 PPP) Milanovic and Yitzhaki (2002) cut offs based on Brazil and Italy comparison 10-100 (2005 PPP) Kharas (2010) definition based on ‘ Developing World Middle Class'

Our purpose in this paper is to suggest that these somewhat pessimistic conclusions are primarily due to an unhelpful conflation of understandings of the global middle class. We wish, therefore, to accomplish two interrelated objectives. First, we seek to clarify possible definitions and understanding of the middle class based on the three categories we have outlined above. All three have a potentially valid underlying motivation, but they are distinct conceptions which direct us to pay attention to different data in different ways.

We will argue that the literature has thus far been using conceptually inappropriate thresholds, especially with regard to Global Middle Class Concept 2 and Global Middle Class Concept 3. For

\footnotetext{
${ }^{8}$ This dependence of patterns upon thresholds is well-known in the case of poverty assessment, where for instance the choice of a higher global poverty line leads to a much less favorable trend of poverty reduction for recent years (within the prevailing money-metric approach) precisely because it affects the regional composition of poverty and different regions have had very different trends of poverty reduction. See for instance (Jayadev et al., 2015).
} 
Global Middle Class Concept 1, based on population-based relative criteria, we will discuss possible choices of threshold and their motivation, and argue that some are better founded than others. For Global Middle Class Concept 2, based on absolute criteria, we do similarly, and argue that we ought to more carefully identify substantively meaningful 'middle class-specific consumption baskets' to obtain a better understanding of its size and evolution across the world over time. Finally, for Global Middle Class Concept 3, after surveying the considerations involved, we suggest that it may not be appropriate to use PPP rates at all and that the appropriate comparison would be to use market exchange rates . Using preferred definitions for each of the concepts, we use material from the newly developed Global Consumption and Income Project to identify the size and composition of the global middle class and its evolution over time based on thresholds that we consider more plausible, although they should still be viewed as highly tentative.

The Global Consumption and Income Project (GCIP) consists of two linked databases- the Global Income Dataset and the Global Consumption Dataset, which together allow for a more detailed portrait of consumption and income of persons over time, within and across countries around the world, than has previously been available. The benchmark version estimates the monthly real consumption and income (in $\$ 2005$ PPP) for quantiles of the population (a consumption/income profile) of the vast majority of countries in the world (around 145) for every year for more than half a century (1960-2013). For a detailed discussion of the relative strengths and limitations of the dataset, see (Lahoti et al., 2014) . Because of the coverage and flexibility of the dataset, we are able to generate portraits using standard PPP comparisons, but also market exchange rates and other concepts, as discussed in section 4 .

\section{The Global Middle Class as the Middle of the Global Con- sumption Distribution}

One plausible definition of the global middle class is that it literally involves those who comprise the middle of the global consumption or income distribution. (We focus on consumption here, although our argument also apply to income). The thought experiment here is to treat the world as a country and to identify bounds around a median. This is in essence the approach espoused by Easterly (Easterly, 2001) who takes the middle to refer to those in the middle three expenditure quintiles. The Palma ratio, which can be used to identify the relatively poor as those below the 40th percentile and the relatively rich as those above the 90th percentile, can be used similarly to identify a middle class specified in relative terms as those with expenditure between the 40th and 90th percentile. A third approach associated with Lester Thurow (Thurow, 1987) and subsequently Birdsall et al.Birdsall et al. (2000) is to define the middle as $75 \%$ to $125 \%$ of the median.

Table 1 identifies the evolution of the global middle class, and the regional contributions to this grouping at three points in time: 1990, 2000 and 2010 as defined by the Thurow criterion. A few points bear mentioning at the outset.

First, when one uses this definition of the 'global middle class', the bounds are narrow and more importantly low, from between $\$ 1.23$ to $\$ 2.05$ in 2005 PPP terms in 1990 to between $\$ 1.47$ to $\$ 2.45$ in 2000 to $\$ 2.22$ to $\$ 3.69$ in 2010 . Put another way, even in 2015 , the vast majority of the world's population live on less than $\$ 4$ in 2005 PPP terms. This has enormous implications for 
the global poverty debate. Because this is such a low level of consumption, it seems strange to call someone who has attained it a member of the middle class $?^{9}$ The difficulties of a purely relative interpretation of the middle class in the global context, where this entails very low absolute levels, are made stark.

Second, in an exercise of this kind involving relative ranking, East Asia and the Pacific plays the starring role in terms of movement into the middle class, reflecting (primarily) the very rapid growth of China. While in 1990, 56\% of the East Asian/Pacific region was below the middle class defined according to these thresholds (stringent in absolute terms), by 2010, only $33 \%$ was below, with the majority $(48 \%)$ actually being above the global middle class. South Asia's relative ranking had fallen, with $75 \%$ being below the threshold of the global middle class in 2010 as compared to $64 \%$ in 1990. Seen another way, the East Asia Pacific Region has managed to reduce the absolute numbers of people considered below the world middle class (from 980 million in 1990 to 700 million in 2010), while in South Asia, the reverse has occurred, with 1.2 billion people in 2010 being considered below the world middle class compared to 720 million in 1990. The relative rise of East Asia and the Pacific has come at the expense of all non-OECD regions: only 10\% of the Sub-Saharan population is above the middle class threshold in 2010 compared with nearly a quarter in 1990, in the Middle-East and North Africa over $20 \%$ of its population in 2010 were considered below the threshold for the middle class compared to only $4 \%$ in 1990 and in Latin America, while $83 \%$ were over the global middle class threshold in 1990, that number is only $70 \%$ in 2010 . Interestingly, the share of East Asia and the Pacific in the global middle class has remained the same (around 40\% in the global middle are from the region), but the proportion above and below the global middle class has reversed (with $40 \%$ above the middle and $20 \%$ below in 2010 compared with $20 \%$ above and $40 \%$ below in 1990). The use of a purely relative thresholds implies that movement into the middle class (in this case of China in particular) necessarily implies that others (such as those living in South Asia and in the Middle East and North Africa or Latin America) must move out of it, either by falling beneath the relative thresholds or rising above them. This could be true even if their incomes had not changed at all, which may seem a somewhat implausible implication of the choice of purely relative thresholds.

Third, despite anxieties as to the Chinese ascent, the relative position of Europe and North America in the global order has barely budged. The whole population of North America has enjoyed and continues to enjoy consumption and income levels above the global middle, while about $90 \%$ of Europe and Central does. These numbers have not changed over the entire period under consideration.

Second, since this involves relative rankings, East Asia and the Pacific has been the major mover at the expense of all the other non industrialized regions, reflecting (primarily) the very rapid growth of China. While in 1990, 56\% of the East Asian/Pacific region was below the middle class, by 2010 , only $33 \%$ was below, with the majority (48\%) actually being above the global middle class. South Asia's relative ranking has fallen with $75 \%$ below the threshold of the global middle class in 2010 compared to $64 \%$ in 1990. Seen another way, the East Asia Pacific Region has managed to reduce the absolute numbers of people considered below the world middle class (from 980 million in 1990 to 700 million in 2010), while in South Asia, the reverse has occurred, with 1.2 billion people in 2010 being considered below the world middle class compared to 720 million in 1990. The relative rise of East Asia and the Pacific has come at the expense of all non-OECD regions: only 10\%

\footnotetext{
${ }^{9}$ (see Reddy and Lahoti (2015) http://ineteconomics.org/ideas-papers/blog/ 1-90-per-day-what-does-it-say for detailed explanation of exactly how low this is)
} 
of the Sub-Saharan population is above the middle class threshold in 2010 compared with nearly a quarter in 1990, in the Middle-East and North Africa over $20 \%$ of its population in 2010 were considered below the threshold for the middle class compared to only $4 \%$ in 1990 and in Latin America, while $83 \%$ were over the global middle class threshold in 1990, that number is only $70 \%$ in 2010. Interestingly, the share of East Asia and the Pacific in the global middle class has remained the same (around $40 \%$ in the global middle are from the region and can ), but the proportion above and below the global middle class has reversed (with $40 \%$ above the middle and $20 \%$ below in 2010 compared with $20 \%$ above and $40 \%$ below in 1990).

Third, despite the anxieties in the West as to the Chinese ascent, the relative rankings of Europe and North America have barely budged. The whole population of North America enjoys consumption and income levels above the global middle, while about $90 \%$ of Europe and Central does. These numbers have not changed over the entire period under consideration.

Taken as a whole then, the story of the global middle class (understood as the middle of the global distribution) in the last 3 decades has been the rapid rise of the (from this point of view, truly) middle kingdom. This can also be seen in the relative positions of distributions as in the Figure 2 . The major mover between 1980 and 2010 is China. In 1980, the entire distribution was below every other country depicted. By 2010, nearly the entire Chinese population is ranked higher than the populations of India, Indonesia and Nigeria, and around half its population enjoys a ranking higher than the lower third of Brazil?s population. This noted, the entire Chinese population, based on percentile data, is still ranked below the entire population of the US.

\section{Global Middle Class Membership as a Sociological Cate- gory}

Assigning membership to the middle class is a difficult task, but one can certainly imagine some common attributes, sociologically understood, that might broadly inform such a definition: e.g. income of a sufficient level, some income security, ownership of durable goods deemed useful for freeing one from drudgery or for providing social status, some disposable income that can be applied to discretionary consumption and leisure activities, access to technology, some level of school education, the perception of being respectable, the ability to participate with a degree of confidence in the life of one?s society and so on.

Conceiving of the middle class as a sociological category with an attendant set of economic attributes, without reducing one to the other, is a plausible approach. Indeed, it is at the core of some of the attempts to describe the global middle class. However, trying to do so using a moneymetric at the outset, without first attempting to assess what the relevant achievements are (as most studies do) is bound to lead to some difficulties.

This can be made clear by a very simple example. Consider first the lower threshold for membership in the global middle class used by several researchers (\$10 PPP per day). This threshold, as noted earlier was chosen because it represented the lowest required level of income to ensure some level of

economic security in Latin America according to the researchers concerned. However, think now of that threshold as applied to the numeraire country, the U.S (since the international dollar used to define standard PPPs is deemed by definition to be equal in purchasing power to the U.S dollar). 


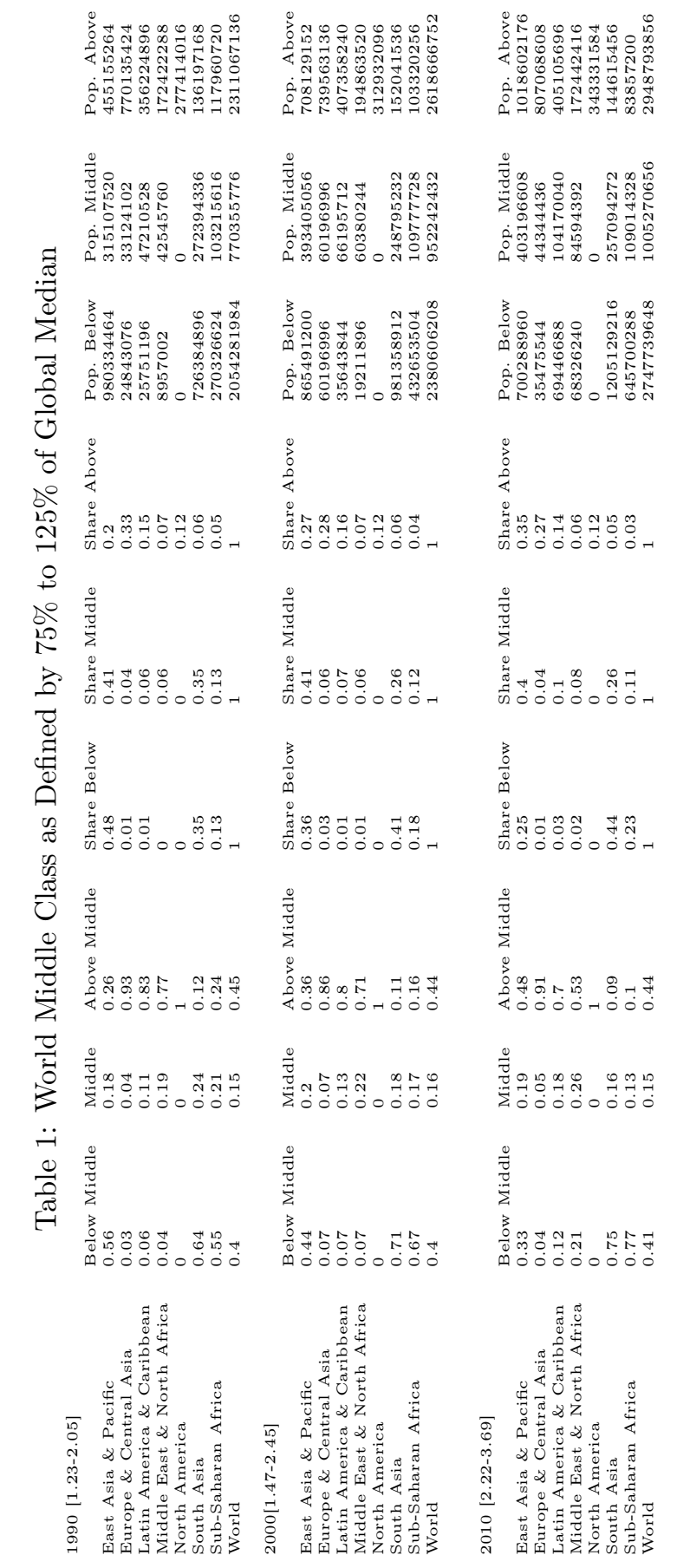


Figure 2: Relative Rankings of Countries and Percentiles in the World Distribution: 1980 and 2010
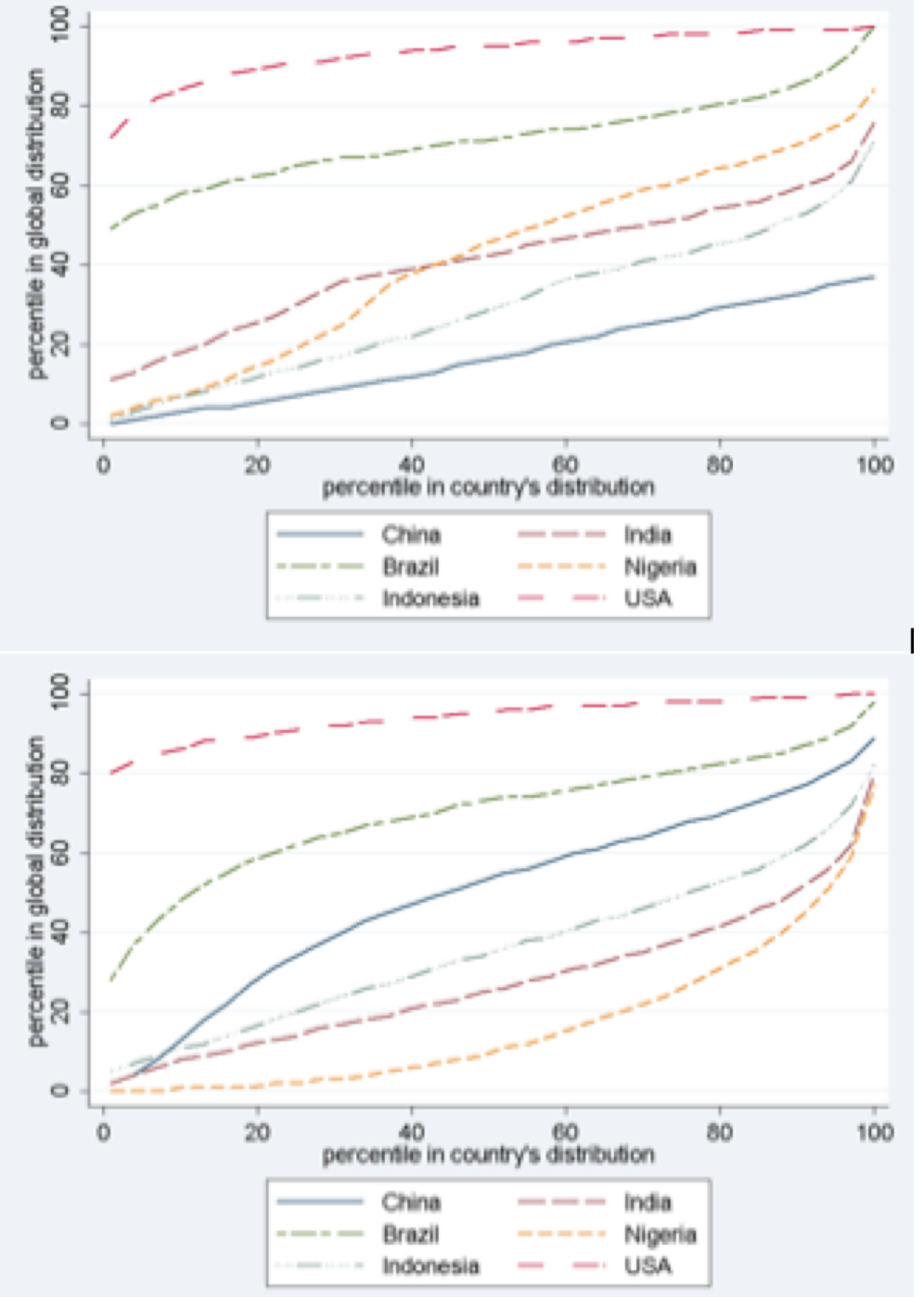

The Chinese catch up: Upper panel: Distribution in 1980. Lower Panel: Distribution in 2010. All figures in $\$ 2005$ PPP authors' calculation. 
Those living on $\$ 10$ a day in the U.S cannot conceivably be called middle class. If one presumes a forty hour working week at minimum wage, an individual with $\$ 10$ PPP income a day would be making eight times less than the prevailing federal minimum wage, and would be make about a third of of the $\$ 12,071$ poverty line specified by the census bureau (not to mention much less than unofficial estimates of the living wage)! It is not a defense, as might be thought of at first, to argue that such a comparison is wrongly using Latin American standards to apply to the US case. While it is certainly true that if a US individual earning $\$ 10$ a day were somehow able to teleport to Nicaragua and use the PPP equivalent in local currency, he or she could conceivably have a (low) middle class life (as defined by income security), this is not the counterfactual being considered?we are interested in the number of people enjoying income security wherever they happen to be in the world. In addition, it can be shown that the minimum cost of nutritional adequacy alone in the US approaches $\$ 4-5$ per person per day (in $\$ 2005 \mathrm{PPP}$ ) for middle class membership could hardly suffice for all the other purposes required.

That this kind of identification problem is not simply the result of inappropriately applying developing country patterns to developed counties can be seen by the application of some of these thresholds to other developing countries. Birdsall's hybrid definition (Birdsall, 2010) suggests that India has nomiddle class at all (since the entire population whose consumption is above \$10 PPP per day is in the top 5\% of the population and hence excluded by her definition). And yet it is evident that there are several dozens of millions of people who enjoy some level of income security, leisure, possess consumer durables; whose children go to school and who have aspirations to a better life and career ${ }^{11}$.This tells us, among other things, that there is something wrong not only with the thresholds used but the PPPs.

Why do these thresholds lead to such troubling anomalies? The answer is simply that the cost structures for obtaining a 'middle class life' differs from country to country. \$8 PPP in India may be sufficient to generate income security, allow an individual to obtain some consumer durables and attain other capabilities associated with being middle class; but in order to do this, \$10 PPP may not be sufficient in Latin America, and certainly insufficient in the US or elsewhere. The key point is one that has been made with respect to the poverty line debate (see, among others

This presumes, at the first place, however, a careful assessment and definitions of the capabilities associated with the status of middle class, and while this can certainly be contested, it is necessary to do prior to identifying thresholds. Such exercises have in fact been undertaken in different contexts (Atkinson and Brandolini, 2011; Blank, 2010) seeking to identify how individuals could achieve middle class status given different demographic and cultural factors. Another approach that may not require as much deliberation would be to follow the lead of (Deaton and Dupriez, 2011) who use an Engel curve methodology to identify poverty specific PPPs.

Given the computational and deliberative difficulty of these two approaches, we propose here a rough and ready alternative, primarily as a proof-of-concept providing an initial demonstration of what might be done more carefully in the future. Specifically, we define a basic set of goods and services required for entering the 'middle-class' life and use an online dataset (Numbeo) (www.numbeo.com) to identify the cost of these goods and services across the world in 2015. Numbeo is a "crowdsourced"

\footnotetext{
${ }^{10}$ see The Thrifty Food plan :http://www.cnpp.usda.gov/sites/default/files/usda_food_plans_cost_of_ food/TFP2006Report.pdf

${ }^{11}$ Birdsall calls the grouping of Indians who possess incomes of between $\$ 4$ and $\$ 10$ PPP per day a 'catalytic class' which is neither poor nor middle-class
} 
online database that collects self-reported data on a bundle of goods and services from different cities in the world. The database is generated from approximately 2 million self-reported observations across cities in about 130 countries. Data are reported only if there is a sufficient number of observations and outliers (defined as prices that are above the 80th percentiles and below the 20th percentile of all observations for a city) are dropped. Despite these safeguards, given that the data are entirely self-reported their reliability is therefore potentially questionable. In addition, they are likely to be biased upwards given that individuals likely to input data are typically higher income. While Numbeo is not the only dataset that compares a market basket across cities and countries, others available are either proprietary or have much more limited coverage.

Having noted this, we conducted a Spearman rank correlation test of the most expensive cities in the world as defined by the Numbeo cost of living index on the one hand and two proprietary datasets : the Mercer cost of living database and the UBS cost of living database respectively. (We will extend this in subsequent work to the UN International Civil Service Commission Post Adjustment database). The Spearman rank correlation coefficient was 0.63 between Numbeo and the first and an impressive 0.92 between Numbeo and the second, and the test of independence was decisively rejected in both cases. Despite reasonable misgivings therefore, in our judgment there is no a priori reason to reject the data on the basis of quality.

Since our task is to define a middle-class level of material attainment, we begin by defining the floor for the middle class as the threshold at which a person can cover food and living expenses at a certain level. Specifically, we use the Numbeo data for the cost of an 'Asian' Food basket required to obtain a day's consumption (2300 calories), translate this to monthly costs and add the cost of renting a one bedroom apartment and utilities shared between 2 people. We take the average cost for the living and food basket as specified across all the cities in the Numbeo database to get a country wide estimate of the lower end threshold.

At the other end, to be considered as having achieved middle class status but not to belong to the upper class (i.e. to have not surpassed the middle class ceiling), in our definition a person needs to not be able to afford more than the following market basket of goods: First, a 'western' market basket of goods that yields 2300 calories (Numbeo provides this data) for a person for 30 day period. Second, rent and basic utilities for a 3 bedroom apartment in the city center $/ 2$ (on the assumption that two people share this three bedroom apartment). Third, the person should be able to afford entertainment defined as a meal at a mid-range restaurant/2 (since the meal in Numbeo is for 2 people) per week and 1 movie ticket per week to an international release for 4 weeks each. Fourth, the person should be able to a afford a monthly transportation pass. We use the average across all the cities in each country to generate the average cost of this basket of goods. Anyone whose income is higher than this threshold is considered above the middle class. No provision is made for saving or any other expenditures, and so this is a very conservative range.

The result is that for each country we get a different range in current USD exchange rates associated with the thresholds. This is as we should expect if we are interested in the actual achievements (as we are). The estimates we obtain for the US lead, for example to an interval between $\$ 27$ per person per day and $\$ 63$ per person per day. For India, by contrast, the estimates suggest that to be in this category requires one to have income in an interval between Rs. 345 (at current exchange rates) and Rs. 830. In Germany, the thresholds correspond from 17.4 Euro to 47.6 Euro per person per day at current (2015) market exchange rates.

A few points should be noted. First, the range of thresholds to achieve middle class status as defined 
Table 2: Middle Class Threshold as Defined by Numbeo Basket Cost: Selected Countries

\begin{tabular}{|c|c|c|c|c|c|}
\hline Country & Floor $(\$)$ & Ceiling $(\$)$ & $\%$ Below & $\%$ in Middle & $\%$ above \\
\hline India & 5.3 & 12.7 & $98.6 \%$ & $1.2 \%$ & $0.2 \%$ \\
\hline Pakistan & 6.0 & 15.1 & $99.2 \%$ & $0.7 \%$ & $0.1 \%$ \\
\hline Egypt & 6.6 & 20.8 & $95.6 \%$ & $3.9 \%$ & $0.5 \%$ \\
\hline Bangladesh & 6.6 & 16.4 & $99.2 \%$ & $0.8 \%$ & $0.0 \%$ \\
\hline Uganda & 7.7 & 19.9 & $99.3 \%$ & $0.6 \%$ & $0.1 \%$ \\
\hline Turkey & 8.2 & 20.7 & $62.4 \%$ & $31.8 \%$ & $5.7 \%$ \\
\hline Brazil & 8.6 & 23.4 & $74.4 \%$ & $22.0 \%$ & $3.6 \%$ \\
\hline Mexico & 8.9 & 24.1 & $78.2 \%$ & $18.5 \%$ & $3.3 \%$ \\
\hline Romania & 9.0 & 20.4 & $90.1 \%$ & $9.9 \%$ & $0.0 \%$ \\
\hline Malaysia & 9.5 & 21.8 & $82.6 \%$ & $15.4 \%$ & $2.0 \%$ \\
\hline Kenya & 10.4 & 34.0 & $98.8 \%$ & $1.1 \%$ & $0.1 \%$ \\
\hline South Africa & 10.7 & 25.9 & $94.8 \%$ & $3.6 \%$ & $1.6 \%$ \\
\hline Thailand & 11.0 & 31.0 & $92.2 \%$ & $7.3 \%$ & $0.6 \%$ \\
\hline Portugal & 11.9 & 31.0 & $35.8 \%$ & $49.8 \%$ & $14.4 \%$ \\
\hline Greece & 11.9 & 27.1 & $21.7 \%$ & $55.5 \%$ & $22.8 \%$ \\
\hline Russian Federation & 12.4 & 34.5 & $91.1 \%$ & $8.9 \%$ & $0.0 \%$ \\
\hline Peru & 12.7 & 30.7 & $91.0 \%$ & $8.0 \%$ & $1.1 \%$ \\
\hline Ecuador & 13.0 & 27.3 & $93.3 \%$ & $5.5 \%$ & $1.2 \%$ \\
\hline China & 14.1 & 43.2 & $92.7 \%$ & $7.3 \%$ & $0.0 \%$ \\
\hline Nigeria & 15.6 & 58.8 & $99.8 \%$ & $0.2 \%$ & $0.0 \%$ \\
\hline Spain & 15.8 & 37.2 & $33.5 \%$ & $53.7 \%$ & $12.8 \%$ \\
\hline Germany & 19.5 & 53.4 & $12.4 \%$ & $66.4 \%$ & $21.2 \%$ \\
\hline Sweden & 19.7 & 56.7 & $12.3 \%$ & $71.2 \%$ & $16.5 \%$ \\
\hline Italy & 20.0 & 50.8 & $40.8 \%$ & $51.5 \%$ & $7.6 \%$ \\
\hline France & 21.4 & 52.9 & $18.5 \%$ & $64.3 \%$ & $17.2 \%$ \\
\hline Canada & 22.0 & 48.7 & $14.3 \%$ & $51.4 \%$ & $34.3 \%$ \\
\hline New Zealand & 22.1 & 55.2 & $0.0 \%$ & $23.3 \%$ & $76.7 \%$ \\
\hline Netherlands & 22.7 & 59.6 & $24.0 \%$ & $64.1 \%$ & $11.9 \%$ \\
\hline Denmark & 23.0 & 65.7 & $7.5 \%$ & $68.4 \%$ & $24.1 \%$ \\
\hline Belgium & 23.3 & 57.0 & $22.2 \%$ & $62.0 \%$ & $15.8 \%$ \\
\hline Korea, Rep. & 23.4 & 61.9 & $57.4 \%$ & $39.1 \%$ & $3.5 \%$ \\
\hline Japan & 24.4 & 67.0 & $31.1 \%$ & $61.1 \%$ & $7.8 \%$ \\
\hline Australia & 26.3 & 66.4 & $12.6 \%$ & $57.8 \%$ & $29.6 \%$ \\
\hline United Kingdom & 27.5 & 66.7 & $18.9 \%$ & $58.5 \%$ & $22.7 \%$ \\
\hline United States & 27.7 & 62.3 & $17.7 \%$ & $50.0 \%$ & $32.3 \%$ \\
\hline Norway & 31.4 & 82.7 & $25.3 \%$ & $64.4 \%$ & $10.2 \%$ \\
\hline
\end{tabular}


by the market basket of goods is very wide between countries and within them, when compared at market exchange rates. Second, industrialized countries have a substantial proportion of their population in this middle class (from around $50 \%$ in the US to $71 \%$ in Sweden). Interestingly, the Anglo-saxon countries have smaller middle classes than continental Europe, but a larger proportion that is above. Another important consideration is that by this measure poorer countries do not have a meaningful middle class to speak of-with only 1 to $2 \%$ of the population enjoying consumption levels that would put them in this range. This is not surprising however, given that the countries are, indeed poorer-but it is also likely partly the artifact of the data collection procedure, since the data are generated from cities which will likely underestimate the number of people who have a middle class lifestyle in countries with larger rural populations. There are also reasons to think that survey data in developing countries may generally underestimate middle and upper class consumption and income, perhaps severely in many cases.

Partly in response to this, we undertake a rudimentary adjustment and define the lower threshold to be .5 times the floor market basket of goods to account for the middle class who are not in cities or who are otherwise under-represented by survey data. This multiplicative factor is admittedly arbitrary and further refinements can certainly be made. Note in particular that for richer countries in which the population does live in cities, this has the effect of including people who are below the threshold required for a middle class basket of goods in urban areas . This measure may underestimates the urban poor in developing countries, potentially counting some of them as belonging to the urban middle class (if we take the view that falling beneath the lower threshold for middle class membership makes one poor, which is a separate taxonomic decision and is not a necessary one; one might, for instance think of some people who are just above the poverty line still not having attained the requirements for 'respectable' middle class membership).

At the other threshold, given that people have disposable income for vehicles or clothing or other goods as well as some savings and still be broadly middle class but not affluent according to prevailing perceptions (consider, for instance, a middle-tier civil servant living on her official salary alone), we suggest an expanded threshold of 1.5 times the ceiling required. This multiplicative factor is arbitrary too, but the range of the [0.5 floor basket of goods- 1.5 ceiling basket of goods] provides an expanded middle class definition which we think roughly plausible, and informative.

Using this expanded understanding of the middle class, we arrive at another set of estimates by country for 2015 as in table 3 .

Predictably, the adjustment leads to a sharp fall in the number of people considered to be below middle class in advanced industrialized countries (often to zero) while expanding the proportion of the middle class in lower income countries. This may be too expansive a definition for advanced countries, but on the other hand may be more effective in capturing the middle class in less urbanized and poorer countries.

Finally, we can repeat the exercise we did with PPP rates that shows the size and contribution of various regions to the global middle class in 2015 using this achievement based definition of the middle class. The results are in figure 3 below.

The urban middle class thresholds provided by Numbeo suggest a widely variant membership across the world. Overall, only about $13 \%$ of the world's population enjoy this status. Unsurprisingly, North America (with 50\% of its population) and Europe with $33 \%$ have the largest numbers, while South Asia and Sub-Saharan Africa have very small numbers (on the order of $1 \%$ ) who attain this 
Table 3: Expanded Middle Class Threshold as Defined by Numbeo Basket Cost: Selected Countries

\begin{tabular}{|c|c|c|c|c|c|}
\hline Country & Floor $(\$)$ & Ceiling $(\$)$ & $\%$ Below & $\%$ in Middle & \%above \\
\hline India & 2.7 & 19.0 & $93.6 \%$ & $6.3 \%$ & $0.1 \%$ \\
\hline Pakistan & 3.0 & 22.6 & $95.3 \%$ & $4.7 \%$ & $0.0 \%$ \\
\hline Egypt & 3.3 & 31.2 & $83.3 \%$ & $16.5 \%$ & $0.2 \%$ \\
\hline Bangladesh & 3.3 & 24.7 & $95.3 \%$ & $4.7 \%$ & $0.0 \%$ \\
\hline Uganda & 3.9 & 29.9 & $97.2 \%$ & $2.8 \%$ & $0.0 \%$ \\
\hline Turkey & 4.1 & 31.0 & $25.2 \%$ & $72.6 \%$ & $2.2 \%$ \\
\hline Brazil & 4.3 & 35.1 & $39.3 \%$ & $59.2 \%$ & $1.5 \%$ \\
\hline Mexico & 4.4 & 36.2 & $44.6 \%$ & $53.9 \%$ & $1.5 \%$ \\
\hline Romania & 4.5 & 30.6 & $45.0 \%$ & $55.0 \%$ & $0.0 \%$ \\
\hline Malaysia & 4.8 & 32.7 & $41.8 \%$ & $57.9 \%$ & $0.3 \%$ \\
\hline Kenya & 5.2 & 51.1 & $95.0 \%$ & $4.9 \%$ & $0.1 \%$ \\
\hline South Africa & 5.3 & 38.9 & $87.0 \%$ & $12.1 \%$ & $0.9 \%$ \\
\hline Thailand & 5.5 & 46.5 & $70.2 \%$ & $29.7 \%$ & $0.0 \%$ \\
\hline Portugal & 6.0 & 46.4 & $7.1 \%$ & $87.1 \%$ & $5.8 \%$ \\
\hline Greece & 6.0 & 40.7 & $1.2 \%$ & $91.1 \%$ & $7.7 \%$ \\
\hline Russian Federation & 6.2 & 51.7 & $57.3 \%$ & $42.7 \%$ & $0.0 \%$ \\
\hline Peru & 6.4 & 46.0 & $63.0 \%$ & $36.7 \%$ & $0.3 \%$ \\
\hline Ecuador & 6.5 & 41.0 & $74.1 \%$ & $25.5 \%$ & $0.4 \%$ \\
\hline China & 7.1 & 64.8 & $68.9 \%$ & $31.1 \%$ & $0.0 \%$ \\
\hline Nigeria & 7.8 & 88.2 & $98.5 \%$ & $1.5 \%$ & $0.0 \%$ \\
\hline Spain & 7.9 & 55.8 & $6.3 \%$ & $89.8 \%$ & $3.9 \%$ \\
\hline Germany & 9.7 & 80.1 & $0.0 \%$ & $93.0 \%$ & $7.0 \%$ \\
\hline Sweden & 9.9 & 85.1 & $0.0 \%$ & $95.0 \%$ & $5.0 \%$ \\
\hline Italy & 10.0 & 76.3 & $8.0 \%$ & $89.7 \%$ & $2.3 \%$ \\
\hline France & 10.7 & 79.4 & $0.9 \%$ & $94.8 \%$ & $4.2 \%$ \\
\hline Canada & 11.0 & 73.0 & $0.0 \%$ & $87.2 \%$ & $12.8 \%$ \\
\hline New Zealand & 11.0 & 82.8 & $0.0 \%$ & $48.9 \%$ & $51.1 \%$ \\
\hline Netherlands & 11.3 & 89.3 & $0.3 \%$ & $96.2 \%$ & $3.6 \%$ \\
\hline Denmark & 11.5 & 98.5 & $0.0 \%$ & $92.3 \%$ & $7.7 \%$ \\
\hline Belgium & 11.7 & 85.6 & $0.0 \%$ & $94.8 \%$ & $5.2 \%$ \\
\hline Korea, Rep. & 11.7 & 92.9 & $10.4 \%$ & $88.5 \%$ & $1.1 \%$ \\
\hline Japan & 12.2 & 100.6 & $0.0 \%$ & $97.5 \%$ & $2.5 \%$ \\
\hline Australia & 13.2 & 99.7 & $0.0 \%$ & $89.8 \%$ & $10.2 \%$ \\
\hline United Kingdom & 13.7 & 100.1 & $0.0 \%$ & $92.1 \%$ & $7.9 \%$ \\
\hline United States & 13.9 & 93.4 & $0.0 \%$ & $87.2 \%$ & $12.8 \%$ \\
\hline Norway & 15.7 & 124.1 & $0.5 \%$ & $96.5 \%$ & $3.0 \%$ \\
\hline
\end{tabular}


Figure 3: Global Middle Class with Numbeo Basket, Basic and Expanded
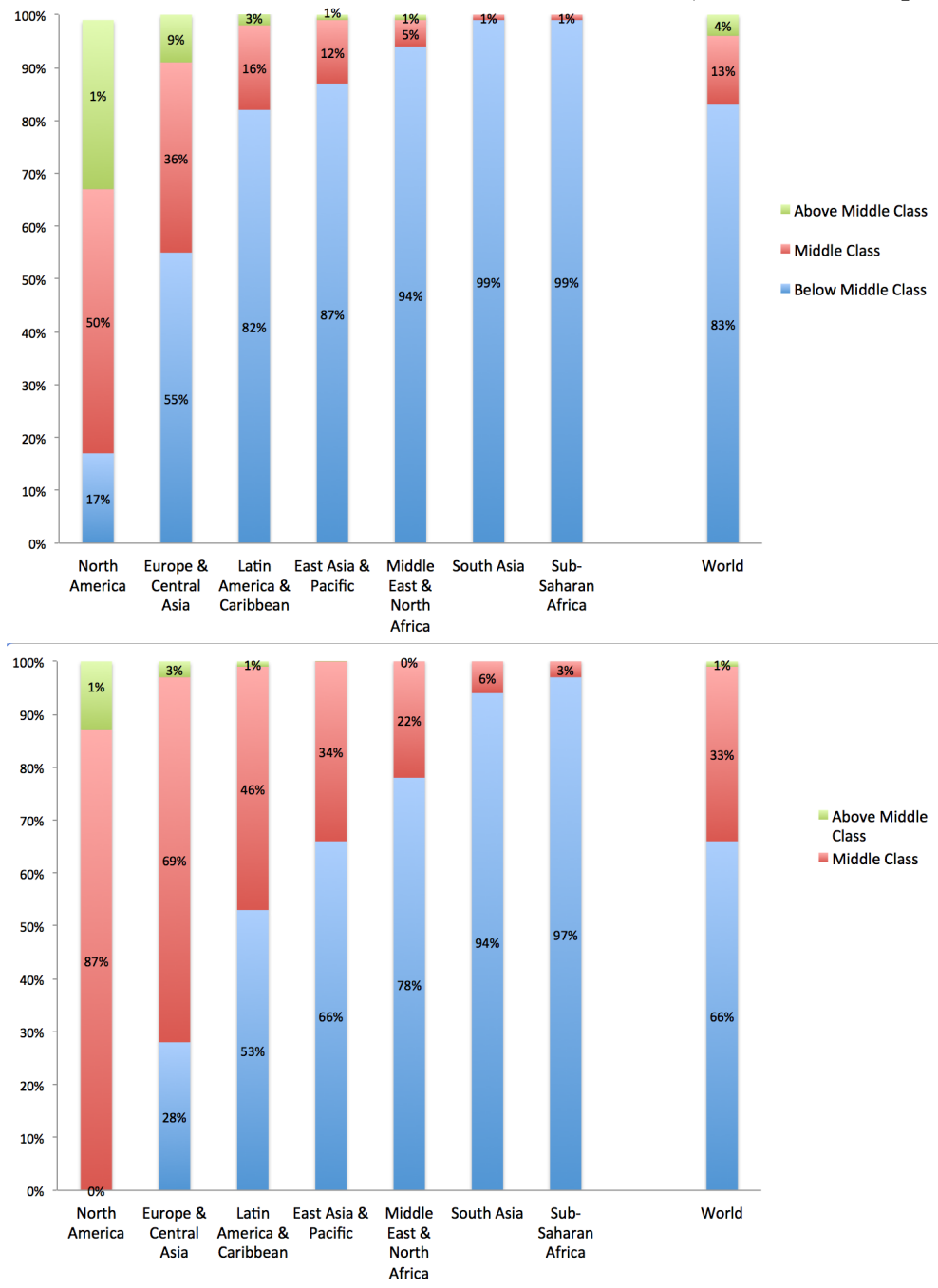

Upper panel: Distribution for Numbeo Basket. Lower Panel: Distribution for 0.5 lower basket-1.5 upper basket.Authors' calculation. 
consumption level. Even if one were to use more generous bounds (as in the second panel), this does not greatly improve the portrait for those two regions. By contrast, with the more expansive bounds, majorities in Europe and North America achieve such a status, while sizeable groups in East Asia, Latin America and the Middle East and North Africa do as well.

\section{The Global Middle Class as Consumers of an International Basket of Goods}

We move finally to the third, consumer market specific definition of the global middle class. This is a notion that is the staple of the business press: the global middle class defined as those who demand international goods and services ${ }^{12}$. Attempts to measure the size of this group in different countries have been varied and use different approaches and regional foci, but all aimed to examine the size of the global consuming middle class (Corrales et al., 2006, Court and Narsimhan, 2010, Dadush and Ali, 2012, Kamakura and Mazzon, 2013).

This is certainly a valid grouping to be concerned with, but it is not entirely clear how to measure their size. If the global elite and possibly the global middle class increasingly consume very similar things, even more similar perhaps than the various "subsistence" levels around the world, then the correct strategy is not to use PPP adjusted measures but simply use exchange rates and identify those who achieve a certain level of consumption of an international basket of goods. If the goods are tradable, one should not expect vast differences in the international cost of these goods across countries. Given that the major interest is in the ability to purchase goods and services that could be afforded by OECD, we estimate the global middle class defined as the middle of the OECD distribution (the middle $40 \%$ ) of OECD consumption, this time using market exchange rates rather than PPP values. This is in table 4 below.

The startling point to note here is the fact that the (only) movement are within the wealthy countries. Latin America has only about 3\% of its population in the OECD middle class; East Asia and the Pacific has only about $7 \%$ of its population, while Sub-Saharan Africa and India have none, whether one is using 1990 exchange rates or 2010 exchange rates to compare the relative distributions. Across the world, only $12 \%$ enjoy consumption levels of the middle class of the OECD.

The breathless anticipation of the new consumer global order centered in China and other emerging economies, endlessly repeated in the business press then, may be a case of willful self-delusion. But the implications go beyond the fact that multinationals will not find as large markets as the business press has suggested exists in emerging markets. The critical issue from the macroeconomic perspective is that at least in the medium term, one cannot expect any replacement from the rest of the world for consumer demand from the OECD. Given this, if one needs to conceive of sources of global aggregate demand, the consumer in the OECD remains the key element in any sort of rebalancing of demand.

\footnotetext{
${ }^{12} \mathrm{An}$ academic, when interviewed notes for example that "There is a demand argument, and if I were at VW, Nestle, Dunkin' Donuts or Ikea, that's what I would be interested in" (Christian Meyer quoted in (Rosenbaum 2013).
} 


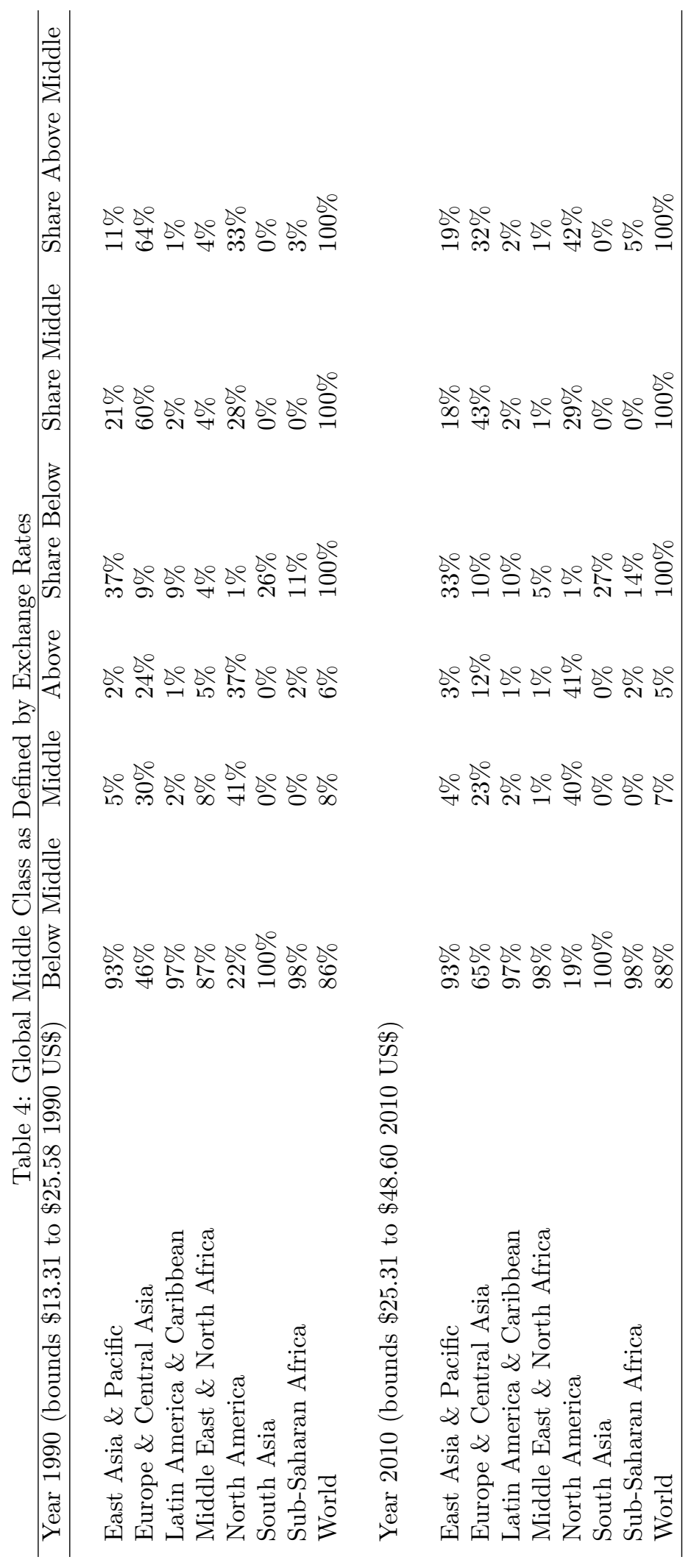




\section{Country}

Brazil

China

France

Germany

India

South Africa

Sweden

United Kingdom

United States
Table 5: Middle Class using Various Thresholds

GMC1 GMC2

$\begin{array}{lllllllll}\text { Below } & \text { Middle } & \text { Above } & \text { Below } & \text { Middle } & \text { Above } & \text { Below } & \text { Middle } & \text { Above } \\ 7.8 \% & 16.3 \% & 75.9 \% & 74.4 \% & 22.0 \% & 3.6 \% & 93.9 \% & 4.5 \% & 1.6 \% \\ 35.7 \% & 19.4 \% & 44.9 \% & 92.7 \% & 7.3 \% & 0.0 \% & 100.0 \% & 0.0 \% & 0.0 \% \\ 0.0 \% & 0.0 \% & 100.0 \% & 18.5 \% & 64.3 \% & 17.2 \% & 22.3 \% & 49.5 \% & 28.2 \% \\ 0.0 \% & 0.0 \% & 100.0 \% & 12.4 \% & 66.4 \% & 21.2 \% & 25.1 \% & 47.7 \% & 27.2 \% \\ 79.2 \% & 14.3 \% & 6.5 \% & 98.6 \% & 1.2 \% & 0.2 \% & 100.0 \% & 0.0 \% & 0.0 \% \\ 49.0 \% & 18.0 \% & 33.0 \% & 94.8 \% & 3.6 \% & 1.6 \% & 97.6 \% & 1.4 \% & 1.0 \% \\ 0.0 \% & 0.0 \% & 100.0 \% & 12.3 \% & 71.2 \% & 16.5 \% & 21.9 \% & 49.4 \% & 28.8 \% \\ 0.0 \% & 0.0 \% & 100.0 \% & 18.9 \% & 58.5 \% & 22.7 \% & 21.6 \% & 44.6 \% & 33.8 \% \\ 0.0 \% & 0.0 \% & 100.0 \% & 17.7 \% & 50.0 \% & 32.3 \% & 19.4 \% & 40.4 \% & 40.2 \%\end{array}$

GMC 1: PPP Middle Class (\$2005 PPP) for 2010

GMC 2: Numbeo Middle Class (2015)

GMC 3: OECD based global middle class ( $\$ 2010 \mathrm{ER}, 2010)$

\section{Conclusion}

Joseph Stiglitz has spent a substantial amount of time emphasizing a concern with what really happens in people's lives and in measuring the quality of life correctly (Stiglitz et al., 2009). We see our attempt in this article as doing precisely that, and trying to disentangle a muddle that has been created by an inappropriate conflation of the many relevant and competing definitions of the global middle class. In doing so we identified three major definitions: the global middle class as the middle of the global income distribution, the global middle class as a sociological category of people who enjoyed some level of common achievement of goods and services and the global middle class as consumers of an international basket of goods. For the second, undertook an analysis which fixed a set of achievements but which allowed a relevant implicit substantive interpretation. This elides some of the problems associated with the use of PPPs. For the third, we showed that the rest of the world still does not have a substantial proportion of people who can replace the OECD middle class as consumers of a global basket of goods when looked at (as is appropriate) with market exchange rates.

That these distinctions have very strong material impacts on the measurement of the middle class within and between countries can be seen in table 5. Depending on the definition for example, the US has anything between 60 and a 100\% of its population enjoying an income or above that of the global middle class.

Moving forward, it is important that we obtain more disaggregated and spatially differentiated PPPs and that we fully examine the relevant basket of goods to achieve a middle class status across contexts. Joseph Stiglitz's concern with a just society has always been a global one. Correctly identifying and understanding the global middle class may be a necessary step therefore to achieving this. 


\section{References}

Aron, R. (1950). Social structure and the ruling class: part 1. The British Journal of Sociology 1(1), $1-16$.

Atkinson, A. and A. Brandolini (2011). On the identification of the middle class. Working Papers 217, ECINEQ, Society for the Study of Economic Inequality.

Autor, D. H., L. F. Katz, and M. S. Kearney (2008). Trends in us wage inequality: Revising the revisionists. The Review of Economics and Statistics 90(2), 300-323.

Banerjee, A. V. and E. Duflo (2008). What is middle class about the middle classes around the world? The Journal of Economic Perspectives 22(2), 3.

Bardhan, P. (1999). The political economy of development in india: Expanded edition with an epilogue on the political economy of reform in india. OUP Catalogue.

Bardhan, P. K. (1984). Land, labor, and rural poverty: Essays in development economics. Columbia University Press.

Birdsall, N. (2010). The (indispensable) middle class in developing countries; or, the rich and the rest, not the poor and the rest. Equity in a Globalizing World, Ravi Kanbur and Michael Spence, eds., World Bank.

Birdsall, N. (2012). Oops: Economists in confused search for the middle class in the developing world. Views From the Center blog, Center for Global Development.

Birdsall, N., C. Graham, and S. Pettinato (2000). Stuck in the tunnel: Is globalization muddling the middle?

Blank, R. (2010). Middle class in america. Working papers, US Department of Commerce Economics and Statistics Division.

Bourdieu, P. (2011). The forms of capital.(1986). Cultural theory: An anthology, 81-93.

Cashell, B. W. (2008). Who are the "middle class"?

Corrales, B., M. Barberena, and N. Schmeichel (2006). Latin american profile, demographics and socio economic strata. Research paper-ESOMAR:European Society for Opinion and Marketing Research.

Court, D. and L. Narsimhan (2010). Capturing the world's emerging middle class. McKinsey Quarterly.

Dadush, U. B. and S. Ali (2012). In Search of the Global Middle Class: A New Index. Carnegie Endowment for International Peace.

Deaton, A. and O. Dupriez (2011). Purchasing power parity exchange rates for the global poor. American Economic Journal: Applied Economics 3(2), 137-66.

Duclos, J.-Y., J. Esteban, and D. Ray (2004). Polarization: concepts, measurement, estimation. Econometrica, 1737-1772. 
Easterly, W. (2001). The middle class consensus and economic development. Journal of economic growth 6(4), 317-335.

Esteban, J.-M. and D. Ray (1994). On the measurement of polarization. Econometrica: Journal of the Econometric Society, 819-851.

Ferreira, F. H., J. Messina, J. Rigolini, L.-F. López-Calva, M. A. Lugo, R. Vakis, L. F. Ló, et al. (2012). Economic mobility and the rise of the Latin American middle class. World Bank Publications.

Frank, R. H. (2007). Falling behind: How income inequality harms the middle class. University of California, Berkeley Press.

Jayadev, A., R. Lahoti, and S. G. Reddy (2015). Who got what, then and now? a fifty year overview from the global consumption and income project. Technical report, Courant Research Centre: Poverty, Equity and Growth-Discussion Papers.

Kamakura, W. A. and J. A. Mazzon (2013). Socioeconomic status and consumption in an emerging economy. International Journal of Research in Marketing 30(1), 4-18.

Kapsos, S., E. , et al. (2013). Employment and economic class in the developing world. Citeseer.

Kharas, H. (2010). The emerging middle class in developing countries.

Kharas, H. and G. Gertz (2010). The new global middle class: a cross-over from west to east. Wolfensohn Center for Development at Brookings, 1-14.

Lahoti, R., A. Jayadev, and S. G. Reddy (2014). The global consumption and income project (gcip): An introduction and preliminary findings. Available at SSRN 2480636.

Lopez-Calva, L. F. and E. Ortiz-Juarez (2014). A vulnerability approach to the definition of the middle class. The Journal of Economic Inequality 12(1), 23-47.

Lukács, G. and G. Lukács (1971). History and class consciousness: Studies in Marxist dialectics, Volume 215. Mit Press.

Milanovic, B. (2006). Global income inequality: What it is and why it matters. World Bank Policy Research Working Paper (3865).

Milanovic, B. and S. Yitzhaki (2002). Decomposing world income distribution: Does the world have a middle class? Review of Income and Wealth 48(2), 155-178.

Parsons, T. (1940). An analytical approach to the theory of social stratification. American Journal of Sociology, 841-862.

Pressman, S. (2007). The decline of the middle class: an international perspective. Journal of Economic Issues, 181-200.

Quah, D. T. (1996). Twin peaks: growth and convergence in models of distribution dynamics. The Economic Journal, 1045-1055.

Ravallion, M. (2010). The developing world's bulging (but vulnerable) middle class. World Development 38(4), $445-454$. 
Rosenbaum, E. (2013). A new species? the elusive nature of the global middle class. CNBC online.

Runciman, W. G. (1974). Occupational class and the assessment of economic inequality in britain. op. cit.

Stiglitz, J. (2012). The price of inequality. Penguin UK.

Stiglitz, J., A. Sen, J.-P. Fitoussi, et al. (2009). The measurement of economic performance and social progress revisited. Reflections and overview. Commission on the Measurement of Economic Performance and Social Progress, Paris.

Sumner, A. (2012). The buoyant billions: How'middle class' are the new middle classes in developing countries?(and why does it matter?). Center for Global Development Working Paper (309).

Taylor, P., R. Morin, R. F. D’Vera Cohn, R. Kochhar, and A. Clark (2008). Inside the middle class: Bad times hit the good life. Pew Research Center.

Thurow, L. C. (1987). A surge in inequality. Scientific American 256(5), 30.

Wolfson, M. C. (1994). When inequalities diverge. The American Economic Review, 353-358. 